\title{
Interrater Reliability, Prevalence, and Relation to ICD-10 Diagnoses of the Diagnostic Criteria for Psychosomatic Research in Consultation-Liaison Psychiatry Patients
}

\author{
Gian Maria Galeazzi, M.D., Ph.D., Silvia Ferrari, M.D. \\ Andrew Mackinnon, B.Sc., Ph.D., Marco Rigateli.i, M.D.
}

\begin{abstract}
The Diagnostic Criteria for Psychosomatic Research (DCPR) have been proposed by an international group of psychosomatic investigators as an operationalized tool for the assessment of psychological distress in medical patients. The aims of the present study were to evaluate interrater reliability, the distribution of DCPR syndromes, and their relationship with ICD.10 diagnostic categories. One hundred consecutive patients who were referred for psychiatric consultation in a university general hospital consented to assessment for DCPR syndromes as elicited in a joint interview conducted by two researchers. The results showed excellent interrater agreement, with kappa values for the II DCPR syndromes ranging from 0.69 to 0.97. More patients met criteria for one or more of the DCPR (87\%) than for an ICD-IO diagnosis (75\%). Four DCPR syndromes were particularly prevalent: demoralization, alexithymia, illness denial, and type $A$ behavior. DCPR criteria appear to be a useful, reliable, and promising approach in the assessment and description of psychological distress in medical patients. They may serve as a focus of intervention studies in this population.

(Psychosomatics 2004; 45:386-393)
\end{abstract}

$\mathrm{C}$ linical wisdom and research findings confirm that formally diagnosed psychiatric disorders, level and type of psychological distress, disrupted attachment and relational patterns, poor social support, and dysfunction in access and utilization of the health care system all exert an important effect on subjective expcrience (as shown, for example, by quality-of-life measures) and the medical outcome of diseases. ${ }^{1,2}$

The most popular framework used to encompass all of these multiple factors interacting to shape the course and

Received March 21, 2003; revision received Sept. 20, 2003; accepted Oct. 17, 2003. From the Consultation/Liaison Psychiatry Service, Department of Neuroscience TCR. Section of Psychiatry, University of Modena and Reggio Emilia, Modena, Italy; and the Department of Psychological Medicine, Monash University, Parkville, Australia. Address correspondence to Dr: Galeazri, Dipartimento di Neuroscicnze TCR, Clinica Psichiatrica, Via del Pozzo-71, 41100-Modena, Italy; galeazzi@unimo,it (c-mail).

Copyright 2004 The Academy of Psychosomatic Medicine. prognosis of physical illnesses is the biopsychosocial model. However, Oken ${ }^{2}$ noted, "The problem with such an overarching model is its very generality. What is required are operational concepts derived from the model that are applicable to the practical tasks of medicine." This problem is particularly apparent in the field of psychosomatic medicine, in which a number of criticisms have been made about the adequacy of the two most widely used diagnostic systems for psychiatric disorders-DSM-IV ${ }^{3}$ and ICD$10^{4}$ - in characterizing psychosocial problems in the medically ill. ${ }^{5,6}$

In fact, the definition of psychiatric disorders presenting with predominantly somatic symptoms within DSMIV and ICD-10, such as somatoform disorders, has significant shortcomings. These definitions tend to be either too restrictive in privileging the specificity and validity of diagnosis (as in somatization disorder) and operate either to exclude somatic pathological processes in an absolute man- 
ner or involve a complex clinical judgment requiring that suffering or impairment is in excess of what would be expected due to the somatic condition. In 1995, an international consortium of psychosomatic investigators ${ }^{7}$ drawing on this type of criticism of DSM definitions of somatoform disorders, psychological factors affecting medical conditions, and adjustment disorders and corresponding ICD-10 categories, ${ }^{8-10}$ suggested that a more useful approach to delineating psychological distress in patients with somatic ailments would be operationalizing and studying the distribution of so-called "psychosomatic syndromes." They developed sets of criteria for 12 syndromes called the Diagnostic Criteria for Psychosomatic Research (DCPR). Four of the DCPR were designed as better-defined alternatives to the poorly delineated DSM-IV category of "Psychological factors affecting medical conditions." These factors were alexithymia, type A behavior, irritable mood, and demoralization. The other eight syndromes were intended to replace and expand the DSM somatoform disorders chapter and included disease phobia, thanatophobia (phobia of death), health anxiety, illness denial, functional somatic symptoms secondary to a psychiatric disorder, persistent somatization, conversion symptoms, and anniversary reaction. Each syndrome was defined by a categorical set of operationalized criteria. The symptom criteria of the 12 syndromes are presented in Table 1 .

The majority of the symptom criteria need to be wholly fulfilled to qualify the subject as being affected by the respective syndrome (i.e., following a monothetic approach), while for alexithymia, type A behavior, and conversion symptoms, different combinations of fulfilled criteria are possible (thus, following a polythetic approach). According to Fava et al., ${ }^{7}$ the prevalence of these syndromes could be compared across different medical conditions in a reliable way. The psychological processes captured by the syndromes are hypothesized to play a role in aggravating disability, worsening quality of life, and influencing outcome in a variety of clinical situations. ${ }^{10}$ This syndromal approach avoids the risk of focusing on strictly defined symptom-based specific disorders, such as chronic fatigue syndrome or irritable bowel syndrome, which typically show substantial co-occurrence of psychopathological comorbidity ${ }^{11,12}$ and are often prematurely attributed to hypothesized somatic factors. ${ }^{13}$

Since their publication, the DCPR have been applied to a variety of clinical populations, including patients with functional gastrointestinal disorders, ${ }^{14,15}$ heart transplantation recipients, ${ }^{16}$ patients with endocrinological disorders, ${ }^{17}$ and cancer. ${ }^{18}$ These studies have demonstrated that the joint use of DSM and DCPR criteria improves the identification of psychological factors and assists the evaluation of psychological distress in the conditions studied. The DCPR-identified conditions that were subthreshold according to DSM criteria were ascertained by using its criteria.

Data from two studies ${ }^{15,19}$ have also demonstrated good criterion-related validity of the DCPR for alexithymia when compared with Toronto Alexithymia Scale scores.

The aim of this study was to evaluate the feasibility of the application of the DCPR in the setting of consultation-liaison psychiatry patients, to compare the distribution of ICD-10 psychiatric diagnoses with that of DCPR syndromes, and to evaluate interrater reliability of the assessment of DCPR syndromes by using a structured interview.

\section{ME'THOD}

\section{Patients}

Inpatients $(\mathrm{N}=101)$ were consecutively recruited from among those referred for psychiatric consultation to the consultation-liaison psychiatry service of Modena General Hospital from all nonpsychiatric wards. Patients were referred to the research team as suitable for interviewing by the consultant psychiatrist if they fulfilled the following inclusion/exclusion criteria: older than 18 years, able to speak fluent Italian, without significant sensory or expressive communication impediments, and not delirious or experiencing significant physical pain. Written informed consent was obtained from all patients. Six other patients approached (four women and two men) declined consent and gave the reason of being uninterested $(\mathrm{N}=4)$, feeling too tired $(\mathrm{N}=1)$, and having just had a gastroscopic examination $(\mathrm{N}=1)$. No data were collected for these patients. One patient (a 23-year-old woman) withdrew her consent during the interview because of fatigue, leaving a study group of 100 .

The patients were 35 men and 65 women, with a mean age of 54.0 years ( $\mathrm{SD}=17.5$, range $22-85) ; 57$ were married or living in a de facto relationship, and the remaining 43 were either single $(N=15)$, divorced $(N=8)$, or widowed $(\mathrm{N}=20)$. The mean number of years of education was $8.2(\mathrm{SD}=3.9)$. Forty-six subjects were old-age pensioners, 30 were in paid employment, 10 were homemakers, eight were unemployed, and six were self-employed. They were referred to psychiatric consultation by their treating physicians for the following reasons: ascertainment of suspected psychiatric conditions $(\mathrm{N}=51)$, suspected psychogenic nature of somatic symptoms $(\mathrm{N}=32)$, 


\section{ICD-10 and Diagnostic Criteria for Psychosomatic Research}

TABLE 1. Diagnostic Criteria for Use in Psychosomatic Research

\begin{tabular}{|c|c|}
\hline $\begin{array}{l}\text { Psychosomatic } \\
\text { Syndromes }\end{array}$ & Diagnostic Criteria \\
\hline Alexithymia & $\begin{array}{l}\text { At least three of the following six characteristics must be present: } \\
\text { 1. Inability to use appropriate words to describe emotions } \\
\text { 2. Tendency to describe details instead of feelings } \\
\text { 3. Lack of a rich fantasy life } \\
\text { 4. Thought content associated more with external events than fantasy or emotions } \\
\text { 5. Unawareness of the common somatic reactions that accompany the experience of a variety of feelings } \\
\text { 6. Occasional but violent and often inappropriate outbursts of affective behavior }\end{array}$ \\
\hline Type A behavior & $\begin{array}{l}\text { - At least five of the following nine characteristics should be present: } \\
\text { 1. Excessive degree of involvement in work and other activities subject to deadlines } \\
\text { 2. Steady and pervasive sense of time urgency } \\
\text { 3. Display of motor-expressive features (rapid and explosive speech, abrupt body movements, tensing of facial } \\
\text { muscles, hand gestures) indicating a sense of being under time pressure } \\
\text { 4. Hostility and cynicism } \\
\text { 5. Irritable mood } \\
\text { 6. Tendency to speed up physical activities } \\
\text { 7. Tendency to speed up mental activities } \\
\text { 8. High intensity of desire for achievements and recognition } \\
\text { 9. High competitiveness } \\
\text { The behavior elicits stress-related physiological responses that precipitate or exacerbate symptoms of a medical } \\
\text { condition }\end{array}$ \\
\hline Irritable mood & $\begin{array}{l}\text { - A feeling state characterized by an irritable mood that may be experienced as brief episodes in particular } \\
\text { circumstances, or it may be prolonged and generalized; it requires an increased effort of control over temper by the } \\
\text { individual or results in irascible verbal or behavioral outbursts } \\
\text { - The experience of irritability is always unpleasant for the individual, and overmanifestation lacks the cathartic effect } \\
\text { of justified outbursts of anger } \\
\text { - The behavior elicits stress-related physiological responses that precipitate or exacerbate symptoms of a medical } \\
\text { condition }\end{array}$ \\
\hline Demoralization & $\begin{array}{l}\text { - A feeling state characterized by the patient's consciousness of having failed to meet his or her own expectations (or } \\
\text { those of others) or being unable to cope with some pressing problem; the patient experiences feelings of helplessness, } \\
\text { hopelessness, or giving up } \\
\text { - The feeling state should be prolonged and generalized (of at least } 1 \text { month in duration) }\end{array}$ \\
\hline Disease phobia & $\begin{array}{l}\text { - Persistent unfounded fear of suffering from a specific disease with doubts remaining despite adequate examination } \\
\text { and reassurance } \\
\text { - Fears tend to manifest themselves in attacks rather than in constant, chronic worries as in hypochondria; panic attacks } \\
\text { may be an associated feature } \\
\text { - The object of fear does not change with time, and the duration of symptoms exceeds } 6 \text { months }\end{array}$ \\
\hline Thanatophobia & $\begin{array}{l}\text { - Attacks with the sense of impending death and/or conviction of dying soon, even though there is no objective } \\
\text { medical reason for such fear } \\
\text { - Marked and persistent fear and avoidance of news that reminds of death (e.g., funerals, obituary notices); exposure to } \\
\text { these stimuli almost invariably provokes an immediate anxiety response } \\
\text { - The avoidance, anxious anticipation, and distress interfere significantly with the person's level of functioning }\end{array}$ \\
\hline Health anxiety & $\begin{array}{l}\text { - Generic worry about illness, concern about pain, and bodily preoccupations (tendency to amplify somatic sensations) } \\
\text { of less than } 6 \text { months' duration } \\
\text { - Worries and fears readily respond to appropriate medical reassurance even though new worries may ensue after some } \\
\text { time }\end{array}$ \\
\hline Illness denial & $\begin{array}{l}\text { - Persistent denial of having a physical disorder and of the need of treatment (e.g., lack of compliance, delayed seeking } \\
\text { of medical attention for serious and persistent symptoms, counterphobic behavior) as a reaction to the symptoms, } \\
\text { signs, diagnosis, or medical treatment of a physical illness } \\
\text { - The patient has been provided a lucid and accurate appraisal of the medical situation and management to be followed }\end{array}$ \\
\hline $\begin{array}{l}\text { Functional somatic } \\
\text { symptoms secondary to a } \\
\text { psychiatric disorder }\end{array}$ & $\begin{array}{l}\text { - Symptoms of autonomic arousal (e.g., palpitations, sweating, tremor, flushing) or functional medical disorder (e.g., } \\
\text { irritable bowel syndrome, fibromyalgia, neurocirculatory asthenia) causing distress or repeated medical care or } \\
\text { resulting in impaired quality of life } \\
\text { - Appropriate medical evaluation uncovers no organic pathology to account for the physical complaints } \\
\text { - A psychiatric disorder that includes the involved somatic symptoms within its manifestations preceded the onset of } \\
\text { functional somatic symptoms (e.g., panic disorder and cardiac symptoms) }\end{array}$ \\
\hline
\end{tabular}


TABLE 1. Diagnostic Criteria for Use in Psychosomatic Research (continued)

\begin{tabular}{|c|c|}
\hline Persistent somatization & $\begin{array}{l}\text { - Functional medical disorder (e.g., fibromyalgia, fatigue, esophageal motility disorders, nonulcer dyspepsia, irritable } \\
\text { bowel syndrome, neurocirculatory asthenia, urethral syndrome) whose duration exceeds } 6 \text { months, causing distress, } \\
\text { repeated medical care, or resulting in impaired quality of life } \\
\text { - Additional symptoms of autonomic arousal (also involving other organ systems) and exaggerated side effects from } \\
\text { medical therapy are present, indicating low sensations or pain thresholds and high suggestibility }\end{array}$ \\
\hline Conversion symptoms & $\begin{array}{l}\text { One or more symptoms or deficits affecting voluntary motor or sensory function characterized by lack of anatomical } \\
\text { or physiological plausibility and/or absence of expected physical signs or laboratory findings and/or inconsistent } \\
\text { clinical characteristics; if symptoms of autonomic arousal of functional medical disorder are present, conversion } \\
\text { symptoms should be prominent, causing distress or repeated medical care or resulting in impaired quality of life } \\
\text { - At least two of the following features are present: } \\
\text { 1. Ambivalence in symptom reporting (e.g., the patient appears relaxed or unconcerned as he describes distressing } \\
\text { symptoms) } \\
\text { 2. Histrionic personality features (colorful and dramatic expression, language, and appearance; demanding } \\
\text { dependency; high suggestibility; rapid mood changes) } \\
\text { 3. Precipitation of symptoms by psychological stress, the association of which the patient is unaware } \\
\text { 4. History of similar physical symptoms experienced by the patient, observed in someone else, or wished on } \\
\text { someone else }\end{array}$ \\
\hline Anniversary reactions & $\begin{array}{l}\text { - Symptoms of autonomic arousal (e.g., palpitations, sweating, tremor, flushing) or functional medical disorder (e.g., } \\
\text { irritable bowel syndrome, fibromyalgia, neurocirculatory asthenia) causing distress, repeated medical care, or } \\
\text { resulting in impaired quality of life } \\
\text { - Appropriate medical evaluation uncovers no organic pathology to account for the physical complaints } \\
\text { - Symptoms began when the patient reached the age or on the occasion of the anniversary when a parent or a close } \\
\text { family member developed a life-threatening illness and/or died; the patient is unaware of such an association }\end{array}$ \\
\hline
\end{tabular}

aModified from Fava et al., 1995.

positive psychiatric history $(N=6)$, relational problems $(\mathrm{N}=4)$, pre-orthotopic liver transplantation psychiatric assessment $(\mathrm{N}=2)$, other $(\mathrm{N}=5)$.

\section{Assessment}

A clinical consensus psychiatric diagnosis according to ICD-10 criteria was available for all patients because of the standard psychiatric consultation and a joint discussion between the consultant psychiatrist and a senior resident in psychiatry performing the consultations. Modena General Hospital's consultation-liaison psychiatry service has achieved high interrater reliability for ICD-10 diagnoses in previous international multicenter research studies. ${ }^{20,21}$

Patients were interviewed by two researcher pairs composed of a consultant psychiatrist and a third-year psychiatry resident on the same or subsequent day to the standard psychiatric consultation. The researchers were acquainted with the DCPR literature and had attended a 1-day training course on DCPR and the administration of the Italian version of the Structured Interview for DCPR (available on request from the first author), which was used to obtain the DCPR diagnoses. The interview is composed of 58 questions with yes or no answers. During the joint interviews, questioning was alternated so that one researcher conducted the entire interview, but each made independent separate notations and evaluations of patient answers. The criteria for "Functional somatic symptoms secondary to a psychiatric disorder" were omitted since the interviewers did not have the necessary information to make this diagnosis. In particular, they could not rate the criterion for this syndrome in requiring that a psychiatric disorder preceded the onset of functional somatic symptoms. The ICD-10 diagnoses were not known to the researchers at the time of the interview, but a copy of each patient's structured referral form to the consultation-liaison psychiatry service reporting basic medical information and the reason for referral was given and known to them in order to locate and approach candidates for the interview.

\section{Statistical Analysis}

Descriptive and agreement statistics were calculated using SPSS software version 10.

\section{RESULTS}

Table 2 shows ICD-10 psychiatric diagnoses: one-quarter of the patients failed to meet criteria for any psychiatric diagnosis. In subjects identified as suffering from a psychiatric disorder, the most prevalent diagnostic group had neurotic, stress-related, and somatoform disorders (F40- 
$48, N=54)$ followed by mood disorders $(F 30-39, N=12)$. Accordingly, Table 2 subdivides these two diagnostic groups in greater detail.

The ICD-9 somatic diagnoses noted by the referring physicians as the caluse of admission at the time of psychiatric consultation are presented in Table 3. It is interesting to note that a large proportion of patients $(\mathrm{N}=38)$ were not found to be suffering from a specific physical disorder: 17 patients were admitted because of "symptoms, signs, and ill-defined conditions" (categories 780-799 of ICD-9), and 21 received no specific medical diagnosis.

An interrater reliability coefficient, kappa, was calculated for each of the DCPR diagnoses. This indicated good to excellent agreement between raters: disease phobiat kappa $=0.97$, thanatophobia kappa $=0.92$, type $\mathrm{A}$ be- havior kappa $=0.92$, illness denial kappa $=0.90$, demoralization kappa $=0.90$, anniversary reaction kappa $=0.90$, health anxiety kappa $=0.89$, alexithymia kappa $=0.89$, conversion symptoms kappa $=0.82$, persistent somatization kappa $=0.70$, and irritable mood kappa $=0.69$.

Patients were assigned one or more DCPR diagnoses on the basis of positive concordance between the two raters. Table 4 displays these diagnoses, ranked according to their frequency. Demoralization, alexithymia, and illness denial were the most common syndromes, with 39, 30, and 29 subjects, respectively, meeting criteria for these diagnoses. Anniversary reaction and conversion symptoms were uncommon, with only 10 and five patients, respectively, assessed as affected by these difficulties.

Table 5 shows the percentages of participants with the

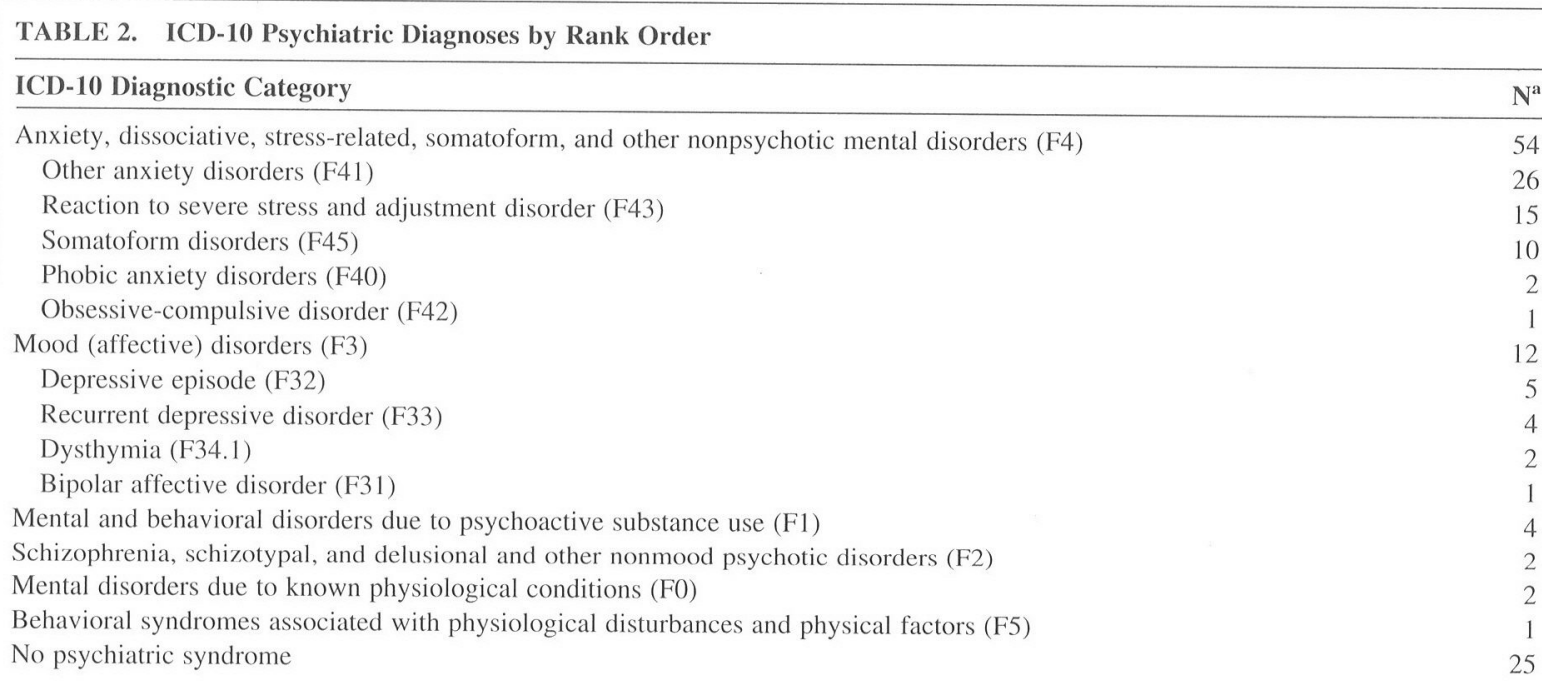

"Because $\mathrm{N}=100$, these figures are also percentages.

TABLE 3. ICD-9 Somatic Diagnoses by Rank Order

\begin{tabular}{ll}
\hline Somatic Diagnosis & $\mathrm{N}^{\mathrm{a}}$ \\
\hline
\end{tabular}

Symptoms, signs, and ill-defined conditions (780-799)

Headache (346)

Chronic cardiovascular diseases (390-459)

Endocrinopathies (240-279)

Neoplasms (140-239)

Other neurological syndromes (320-359)

Chronic liver disease (571)

Diseases of connective tissue (710-739)

Injuries (800-958)

HIV (042)

Others

No somatic diagnosis

${ }^{\text {a Because } \mathrm{N}}=100$, these figures are also percentages.
TABLE 4. Diagnostic Criteria for Psychosomatic Research (DCPR) Diagnoses in Order of Prevalence

\begin{tabular}{lcc}
\hline Diagnosis & $\begin{array}{c}\text { Patients } \\
(\boldsymbol{\%})\end{array}$ & $\begin{array}{c}\text { Total Diagnoses } \\
(\mathbf{N}=\mathbf{2 1 9})(\boldsymbol{\%})\end{array}$ \\
\hline Demoralization & 39 & 17.8 \\
Alexithymia & 30 & 13.2 \\
Illness denial & 29 & 13.2 \\
Type A behavior & 25 & 11.4 \\
Health anxiety & 21 & 9.6 \\
Disease phobia & 19 & 8.7 \\
Irritable mood & 15 & 6.9 \\
Persistent somatization & 14 & 6.3 \\
Thanatophobia & 13 & 5.5 \\
Anniversary reaction & 10 & 4.6 \\
Conversion symptoms & 5 & 2.3 \\
Patients with no DCPR diagnosis & 13 &
\end{tabular}


most frequent ICD-10 psychiatric diagnostic categories who also had the most frequent DCPR diagnoses. Illness denial and type A behavior were found to be frequently associated with an F4 anxiety diagnosis, whereas demoralization and alexithymia corresponded frequently with an F3 mood disorder.

Table 6 presents an analysis of DCPR diagnoses that co-occurred with an ICD-10 psychiatric diagnosis. As shown, a large percentage of patients with the most frequent DCPR diagnoses (demoralization, alexithymia, illness denial, and type A behavior) also met criteria for ICD10 diagnoses. Similar associations to those previously illustrated in Table 5 were found, with anxiety disorders particularly common in those with illness denial and type A behavior and mood disorders in those with demoralization and alexithymia.

Finally, Table 7 displays the overlapping rates between the most frequent DCPR diagnoses, that is, the associations between different DCPR diagnoses in the same patients. The most frequent association was between illness denial and type $\mathrm{A}$ behavior.

\section{DISCUSSION}

The present study shows the reliability and applicability of the DCPR to consultation-liaison psychiatry patients re- ferred for psychiatric assessment. This builds upon previously published research, ${ }^{14-18}$ which has demonstrated the use of the criteria in other settings. The reliability of the criteria as elicited by the Structured Interview for the DCPR was found to be high for all of the 11 psychosomatic syndromes analyzed (kappa values higher than 0.70 , except for irritable mood, which achieved an acceptable kappa $=0.69$ ). To our knowledge, this is the first study to investigate the reliability with which the DCPR criteria can be elicited and evaluated. DCPR interrater reliability appears to be higher than that achieved for the ICD-10 diagnoses of somatoform disorders (mean kappa $=0.61$ ) and adjustment disorders (mean kappa $=0.54)^{22,23}$ and does well also when compared to DSM categories. ${ }^{24}$

Another notable feature found in this group of nonpsychiatric patients with known or suspected medical conditions was the high prevalence of "psychosomatic" DCPR-positive syndromes. This reflects, in part, the fact that these inpatients were referred to a consultation-liaison psychiatry service by their treating physicians for suspected emotional or behavioral problems. Nevertheless, it highlights the importance of further research into the relationship between psychological factors and medical illness and the need for a more scientific approach to demonstrate their causal links, other than simple "mechanistic evidence." ${ }^{25}$ The DCPR were developed as a complemen-

TABLE 5. Rates of Co-occurrence of Diagnostic Criteria for Psychosomatic Research Syndromes in Patients Meeting Criteria for ICD-10 F4 and F3 Diagnostic Categories

\begin{tabular}{lcccc}
\hline Diagnostic Category & Demoralization & Alexithymia & Illness Denial & Type A Behavior \\
\hline Anxiety, dissociative, stress-related, somatoform, and other & & & & \\
nonpsychotic mental disorders (F4) $(\mathrm{N}=54)$ & 24.8 & 25.9 & 38.9 & 29.6 \\
Mood (affective) disorders (F3) $(\mathrm{N}=12)$ & 58.3 & 41.6 & 25.0 & 8.3 \\
\hline
\end{tabular}

TABLE 6. Rates of Co-occurrence of ICD-10 F4 and F3 Diagnostic Categories in Patients Meeting Criteria for Diagnostic Criteria for Psychosomatic Research Syndromes

\begin{tabular}{lcc}
\hline Syndrome & $\begin{array}{c}\text { Anxiety, Dissociative, Stress-Related, Somatoform, } \\
\text { and Other Nonpsychotic Mental Disorders (F4) }\end{array}$ & 38.5 \\
\hline Demoralization $(\mathrm{N}=39)$ & 46.7 \\
Alexithymia $(\mathrm{N}=30)$ & 70.0 \\
Illness denial $(\mathrm{N}=30)$ & 64.0 \\
Type A behavior $(\mathrm{N}=25)$ & 16.7 \\
\hline
\end{tabular}

TABLE 7. Overlapping Rates Within Diagnostic Criteria for Psychosomatic Research Classification

\begin{tabular}{lcccc}
\hline Symptom & Demoralization $(\mathbf{N}=39)$ & Alexithymia $(\mathbf{N}=\mathbf{3 0})$ & Illness Denial $(\mathbf{N}=30)$ & Type A Behavior $(\mathbf{N}=25)$ \\
\hline Demoralization $(\mathrm{N}=39)$ & & 25.6 & 28.2 & 33.3 \\
Alexithymia $(\mathrm{N}=30)$ & 33.3 & & 36.7 & 20.0 \\
Illness denial $(\mathrm{N}=30)$ & 36.7 & 36.7 & & 81.8 \\
Type A behavior $(\mathrm{N}=25)$ & 52.0 & 24.0 & 36.0 & \\
\hline
\end{tabular}




\section{ICD-10 and Diagnostic Criteria for Psychosomatic Research}

tary integration to DSM criteria for somatoform disorders, adjustment disorders, and psychological factors affecting medical conditions. In addition, the DCPR operationalize traditional psychosomatic constructs but also reflect more recent notions of emotional, cognitive, and behavioral characteristics of medical patients arising specifically out of this controversy. ${ }^{26}$ As a result of these characteristics, it has been proposed that the constant "work in progress" of psychiatric nosography of the DSM could incorporate the DCPR criteria for further research in future editions of the DSM. ${ }^{5}$

As expected, the DCPR were highly prevalent in this consultation-liaison group: all but 13 patients met the criteria for at least one of the 11 syndromes evaluated. In contrast, $25 \%$ failed to meet the criteria for any ICD- 10 psychiatric diagnosis. Other authors ${ }^{14.16}$ have suggested that the DCPR more thoroughly describes the psychiatric morbidity of medical (or supposedly medical) populations than Iraditional psychiatric diagnostic categories. In our study, the number of DCPR diagnoses doubled that of ICD10 diagnoses; elsewhere, the reported ratio was three to one: DCPR diagnoses tripled DSM diagnoses. ${ }^{16}$ The prevalence of DCPR diagnoses is comparable to that found previously in other samples, ${ }^{14,16,18}$ with demoralization the most frequently occurring syndrome found and alexithymia and type A behavior among the top four diagnoses.

Demoralization is often described in the medically ill: $39 \%$ of patients endorsed such difficulties in the present study. Slavney ${ }^{27}$ has pointed out that 1 ) demoralization is not a synonym for adjustment disorder or subthreshold depression and that 2) demoralization should not be considered a straightforward psychiatric disorder but more correctly an understandable psychological reaction to adverse events similar to uncomplicated grief. He also outlines the need to operationalize demoralization and to avoid its nonrecognition or misinterpretation. This study confirms the hypothesis that demoralization is differentiable from depression $^{10,16,27}$ and from the combination of depression and anxiety, ${ }^{28.29}$ with only $18 \%$ of demoralized patients also affected by a mood disorder versus a $58.3 \%$ converse overlap.

Alexithymia is also held to be common in the medically ill population, the construct itself developed and originally related to psychosomatic diseases. ${ }^{30}$ About a third of patients were found to meet the criteria for DCPR-defined alexithymia. The nature of the association between alexithymia and depression is controversial, with researchers holding differing beliefs about the mechanisms underlying the observed comorbidity. ${ }^{31 \cdot 34}$ As with demoralization, our data suggest that alexithymia is common among those with a mood disorder but only a low percentage of alexithymics have a full-blown mood disorder.

Just under one-third of the patients met criteria for illness denial and a quarter for type A behavior. These two syndromes showed a marked association, with the latter exhibiting a strong overlap with demoralization. This is consistent with the concept that type $A$ behavior entails a sense of dissatisfaction with previously attained goals and a sense of urgency to achieve more: these are typical traits seen in the typus melancholicus (a personality constellation considered to be prone to demoralization), whose association with type A behavior has been shown. ${ }^{35}$ In the current study group, these two syndromes tended to cluster in the ICD-10 F4 subcategories.

A number of limitations of this study must be acknowledged. The ICD-10 diagnoses reported were the principal psychiatric diagnoses obtained by routine clinical interview. The reliability of these diagnoses was not assessed as part of this study and may well underestimate the presence of multiple psychiatric diagnoses. The interviewer-auditor design adopted, which tends to produce higher agreement than independent scparate interviews, probably contributed to the high level of agreement observed. The likelihood of agreement was further enhanced by the use of researchers familiar with the DCPR as interviewers. Despite these limitations, this study has demonstrated that the DCPR can be clicited and diagnosed with good interrater reliability when psychosomatic syndromes are rated by using a structured interview. It further supports the DCPR as a viable and reliable system for the assessment of psychological distress in the presence of medical disease. There is a need to test the hypothesis that the typical cognitive and affective styles portrayed by the DCPR syndromes can mediate the psychological effect of medical conditions and explain a fraction of their outcome variance.

The authors thank Olivia Salemi, M.D., and Gaspare Palmieri, M.D., for their help as joint interview raters.

\footnotetext{
References

1. Fava GA, Sonino N: Psychosomatic medicine: emerging trends and perspectives. Psychother Psychosom 2000; 69:184-197
}

2. Oken D: Multiaxial diagnosis and psychosomatic model of disease. Psychosom Med 2000; 62:171-175 
3. American Psychiatric Association: Diagnostic and Statistical Manual of Mental Disorders, 4th ed.-Text Revision (DSM-IVTR). Washington DC, APA, 2000

4. World Health Organization: The ICD-10 classification of mental and behavioural disorders. Geneva, WHO, 1992

5. Wise TN, Birket-Smith M: The somatoform disorders for DSM$\mathrm{V}$ : the need for changes in process and content. Psychosomatics 2002; 43:437-440

6. Fava GA: Beyond the biopsychosocial model: psychological characterization of medical illness. J Psychosom Res 1996; 40:117120

7. Fava GA, Freyberger HJ, Bech P, Cristodolulou G, Sensky T, Theorell T, Wise T: Diagnostic criteria for use in psychosomatic research. Psychother Psychosom 1995; 63:1-8

8. Fava GA: The concept of psychosomatic disorder. Psychother Psychosom 1992; 58:1-12

9. Sensky T: Somatization: syndromes or process? Psychother Psy chosom 1994; 61:1-3

10. Fava GA, Mangelli L, Ruini C: Assessment of psychological distress in the setting of medical disease. Psychother Psychosom 2001; 70:171-175

11. Deary IJ: A taxonomy of medically unexplained symptoms. J Psychosom Res 1999; 47:51-59

12. Nimnuan C, Rabe-Hesketh S, Wessely S, Hotopf M: How many functional somatic syndromes? J Psychosom Res 2001; 51:549--557

13. Feinstein AR: The blame-X syndrome: problems and lessons in nosology, spectrum and etiology. J Clin Epidemiol 2001; 54:433439

14. Porcelli P, De Carne M, Fava GA: Assessing somatization in functional gastrointestinal disorders: integration of different criteria. Psychother Psychosom 2000; 69:198-204

15. Porcelli P, De Carne M: Criterion-related validity of the diagnostic criteria for psychosomatic research for alexithymia in patients with functional gastrointestinal disorders. Psychother Psychosom 2001; $70: 184-188$

16. Grandi S, Fabbri S, Tossani E, Mangelli L, Branzi A, Magelli C: Psychological evaluation after cardiac transplantation: the integration of different criteria. Psychother Psychosom 2001; 70:176-183

17. Sonino N, Ruini C, Ottolini F, Navarrini C, Fava GA: Psychosocial correlates of endocrine disease. Eur Psychiatry 2000; 15(suppl 2):345

18. Grassi L, Porcelli P, Rigatelli M, Ottolini F, Grandi S: Use of the diagnostic criteria for psychosomatic research (DCPR) in medical settings. Psychosom Med 2002; 64:127

19. Fukunishi I, Hosaka T, Aoki T, Azekawa T, Ota A, Miyaoka H: Criterion-related validity of diagnostic criteria for alexithymia in a general hospital setting. Psychother Psychosom 1996; 65:82-85

20. Malt UF, Huyse FJ, Herzog T, Lobo A, Rijssenbeek AJ: The ECLW Collaborative Study, III: Training and reliability of ICD10 psychiatric diagnoses in the general hospital setting: an inves- tigation of 220 consultants from 14 European countries. J Psychosom Res 1996; 41:451-463

21. Rigatelli M, Galeazzi GM, Palmicri G: Consultation-liaison psy chiatry in obstetrics and gynaecology. J Psychosom Obstet Gynaecol 2002; 23:165-172

22. Sartorius N, Ustun TB, Korten A, Cooper JE, van Drimmelen J: Progress toward achieving a common language in psychiatry, II: Results from the international ficld trials of the ICD-I0 diagnostic criteria for research for mental and behavioral disorders. Am J Psychiatry $1995 ; 152: 1427-1437$

23. Regier DA, Kaelber CT, Roper MT, Rae DS, Sartorius N: The ICD-10 clinical field trial for mental and behavioral disorders: results in Canada and the United States. Am J Psychiatry 1994; $151: 1340-1350$

24. Segal DL, Hersen M, Van Hasselt VB: Reliability of the Structured Clinical Interview for DSM-III-R: an evaluative review. Compr Psychiatry 1994; 35:316-327

25. Ketterer MW, Mahr G, Goldberg AD: Psychological factors affecting a medical condition: ischemic coronaric heart disease. J Psychosom Res 2000; 48:357-367

26. Fabbri S, Kapur N, Wells A, Creed F: Emotional, cognitive and behavioural characteristics of medical outpatients: a preliminary analysis. Psychosomatics 2001; 42:74-77

27. Slavney PR: Diagnosing demoralization in consultation psychiatry. Psychosomatics 1999; 40:325-329

28. Angelino AF, Treisman GJ: Major depression and demoralization in cancer patients: diagnostic and treatment considerations. Support Carc Cancer 2001; 9:344-349

29. Clarke DM, Mackinnon AJ, Smith GC, McKenzie DP, Herrman HE: Dimensions of psychopathology in the medically ill: a latent trait analysis. Psychosomatics 2000; 41:418-425

30. Nemiah JC, Sifneos PE: Affect and fantasy in paticnts with psychosomatic disorders, in Modern Trends in Psychosomatic Medicine, vol 2. Edited by Hill OW. London, Butterworths, 1970, pp 26-34

31. Bach M, Bach D: Alexithymia in somatoform disorder and somatic disease: a comparative study. Psychother Psychosom 1996: $65: 150-152$

32. Honkalampi K, Hintikka J, Tanskanen A, Lehtonen J, Viinamaki $\mathrm{H}$ : Depression is strongly associated with alexithymia in the general population. J Psychosom Res 2000; 48:99-104

33. Wise TN, Mann LS, Hill B: Alexithymia and depressed mood in the psychiatric patient. Psychother Psychosom 1990; 54:26-31

34. Parker JDA, Bagby RM, Taylor GJ: Alexithymia and depression: distinct or overlapping constructs? Compr Psychiatry 1991; 32:387-394

35. Fukunishi I, Hattori M, Hattori H, Imai Y, Miyake Y, Miguchi M, Yoshimatsu K: Japanese type A behavior pattern is associated with "typus melancholicus": a study from the sociocultural vicwpoint. Int $J$ Soc Psychiatry 1992; 38:251-256 